Revista de Economia Política, vol. 31, $n^{\circ} 1$ (121), pp. 31-55, janeiro-março/2011

\title{
As convenções de desenvolvimento no governo Lula: um ensaio de economia política
}

FABIO S. ERBER*

Development conventions in Lula's mandates: an essay on political economy. This article analyses the different development proposals put forward during the two Lula Presidential mandates. It is argued that such proposals are structured as "development conventions", which involve different priorities and different solutions to the problem of structural transformation. Their analytical frame is also different as are the interest groups which uphold them. Therefore their epistemology must be placed in the political economy context. It is argued that, notwithstanding the weight gained by a "developmental" convention over the second mandate, a "stability" convention is still hegemonic and commands macroeconomic policies.

Keywords: political economy; economic development; lula government.

JEL Classification: 010; 011; 020; 054.

\section{INTRODUÇÃO}

O objetivo deste ensaio é discutir as concepções de desenvolvimento que se encontram no Brasil contemporâneo. Parte do conhecido dito de Keynes de que, por detrás dos "homens práticos", estão as ideias de economistas, frequentemente mortos há muito tempo. Ou seja, a teoria econômica é importan-

\footnotetext{
* Professor do Instituto de Economia da UFRJ. E-mail: fabio.erber@gmail.com. Uma primeira versão deste artigo foi apresentada no 5o Fórum de Economia da FGV-SP em setembro de 2008 (Erber, 2009). Em outubro de 2009, o artigo foi substancialmente revisto para o IPEA, no âmbito de um Convênio CEPAL/IPEA. A presente versão introduz outras modificações. Agradeço os comentários recebidos no Fórum, notadamente, de Brasílio Sallum Jr., dos técnicos do IPEA, especialmente de André Modenesi, e de Luiz Carlos Bresser-Pereira. O artigo faz parte de uma pesquisa sobre a economia política e a epistemologia da teoria do desenvolvimento, na qual o diálogo com Fabio Sá Earp, Luiz Carlos Prado, Ricardo Bielschowsky e os alunos da pós-graduação em economia do IE são de fundamental importância. No entanto, as opiniões expressas pelo autor são de sua inteira responsabilidade. Submetido: Novem0bro 2009; Aprovado: Dezembro De 2009.
} 
te para a política econômica. No entanto, como advertia Schumpeter, há quase um século, devemos nos precaver contra o "erro intelectualista" - as "ideias dos economistas" têm raízes nos problemas práticos que têm que enfrentar, assim como na filosofia (Schumpeter 1954). ${ }^{1}$ Mesmo a "economia pura", concebida como uma "caixa de ferramentas", é socialmente inserida - "o trabalho analítico principia com material extraído da nossa visão das coisas, e esta visão é, por definição, ideológica" (Schumpeter, 1964, p. 70) e a profissão de economista "desenvolve atitudes relativas às questões políticas e sociais que são similares também por outras razões além das científicas" (ibid, p. 75, ênfase do original). $\mathrm{Na}$ direção inversa, ele (ibid.) aponta para o papel que as teorias e o instrumental econômico desempenham na constituição dos "sistemas de economia política”, como o liberalismo e o socialismo.

Em síntese, parte-se do princípio epistemológico que a Economia é ontológicamente Política. Um dos seus propósitos é contribuir para a discussão dos interesses econômicos que estão subjacentes às teorias sobre os objetivos e procedimentos recomendados para o desenvolvimento brasileiro. Ou seja, move-se na contramão da visão que os conflitos são de ordem técnica.

O objeto do ensaio é o processo de desenvolvimento brasileiro contemporâneo. Pelas suas características, o processo de desenvolvimento traz aos atores sociais uma incerteza substantiva, que não pode ser eliminada pela busca de mais informações e implica problemas de coordenação entre os atores.

Para lidar com os problemas de incerteza e coordenação, as sociedades utilizam instituições - as "regras do jogo". Nos planos cognitivo e comportamental estas regras estão estruturadas por convenções. Formalmente, temos uma convenção se, dada uma população $\boldsymbol{P}$, observamos um comportamento $C$ que tem as seguintes características: (i) $C$ é compartilhado por todos os membros de $\boldsymbol{P}$; (ii) cada membro de $\boldsymbol{P}$ acredita que todos os demais seguirão $\boldsymbol{C}$ e (iii) tal crença dá aos membros de $\boldsymbol{P}$ razões suficientes para adotar $\boldsymbol{C}$ (Orléan, 2004).

Na próxima seção, discute-se, sucintamente, o conceito de convenção, sua utilização na seleção de problemas e soluções e a disputa pela hegemonia entre convenções. O caso brasileiro é tratado na terceira seção, em cinco partes. $\mathrm{Na}$ primeira, é analisada a incerteza vigente à posse do Presidente Lula e o reclamo por uma nova "convenção de desenvolvimento". Nas duas partes seguintes, apresentam-se as duas convenções que se formaram, apoiadas em forças políticas diferentes, denominadas, por razões explicadas no texto, de "institucionalista restrita" e "neodesenvolvimentista". A quarta parte examina as relações entre as duas convenções. A última parte discute brevemente convenções de desenvolvimento alternativas surgidas na sociedade civil. A seção final contenta-se em resumir as conclusões do ensaio.

${ }^{1}$ O livro foi publicado originalmente em 1912. 
Tomemos como ponto de partida uma distinção tradicional entre crescimento e desenvolvimento: o primeiro consiste, essencialmente, em "mais do mesmo", o segundo implica transformações estruturais. Estas transformações fazem com que os atores enfrentem uma incerteza substantiva, que não pode ser eliminada através da busca de mais informações.

Tal incerteza reduz a possibilidade de coordenação das ações dos atores, especialmente das suas estratégias. A sinergia e as externalidades que surgem através da ação conjunta são reduzidas, a mudança torna-se mais lenta e errática.

Instituições provêm a sociedade com meios para lidar com os problemas de incerteza e coordenação - "regras do jogo", na definição de North (1990), amplamente aceita. Tais regras sobre a problemática social derivam de metáforas que são de conhecimento e aceitação gerais e que geram outras metáforas, complementares (Schön, 1968) ou, como argumentam Denzau e North (2004), de "modelos mentais compartilhados".

Tais metáforas servem para definir os problemas, descrevendo o que está errado com a situação presente de tal forma a estabelecer a direção para sua transformação futura, Para cumprir adequadamente os seus papeis de redução de incerteza e aumento de coordenação, tais regras especificam agendas positivas e negativas - uma hierarquia de problemas que devem ser enfrentados (p.ex. controle da inflação, distribuição de renda), soluções para esses problemas que são aceitáveis (p.ex. metas de inflação) ou não (p.ex. controles administrativos de preços), organizações encarregadas (o Banco Central), assim como regras e regulamentos (Regras de Basileia). Ou seja, estabelecem uma ordem para a transformação.

O poder destas regras é substancialmente aumentado se elas obtêm coerência através de uma metáfora histórica - uma história, uma teoria que explica como o presente surgiu a partir do passado e, especialmente, como o futuro será se as regras forem seguidas. Em síntese, uma teleologia.

Este conjunto de regras, as agendas, positiva e negativa, que gera e a teleologia subjacente, constituem uma convenção - uma "representação coletiva" (Jodelet, 1989) que estrutura as expectativas e o comportamento individual, tal como definido na Introdução.

Uma convenção de desenvolvimento, seguindo a definição deste, acima dada, trata das transformações estruturais que devem ser introduzidas na sociedade, estabelecendo o que há de "errado" no presente, fruto do passado, qual o futuro desejável, quais estruturas devem ser mudadas e as agendas de mudança, positiva e negativa.

Uma convenção surge da interação entre atores sociais, mas é externa a esses atores e não pode ser reduzida à sua cognição individual — ou seja, é um fenômeno emergente, em que o todo não é redutível às partes (De Wolf \& Holvoet, 2005). 
A força de uma convenção é proporcional ao tamanho de $\boldsymbol{P}$ e ao poder político e econômico dos seus membros. Tal força proporciona benefícios aos que aderem à convenção e sanciona os que dela se afastam. Em consequência, $P$ contem não apenas "crentes", como "oportunistas", movidos apenas por razões utilitárias (Choi, 1993).

A legitimidade das convenções depende da fé depositada por seus aderentes no seu conteúdo cognitivo e, acima de tudo, da adequação de seus resultados às expectativas dos membros da população $\boldsymbol{P}$.

O conteúdo cognitivo de uma convenção de desenvolvimento ${ }^{2}$ é composto de conhecimentos codificados e conhecimentos tácitos, estruturados por um "núcleo duro", de natureza axiomática, que organiza o conhecimento, e por um "cinturão protetor", que operacionaliza este conhecimento e o adapta às condições específicas.

Parte dos conhecimentos codificados tem origem na ciência, notadamente as ciências sociais - teorias econômicas, sociais e políticas - conhecimentos especializados, elaborados por profissionais no âmbito da academia internacional. A partir desta "versão erudita" (Sá Earp, 2000), normalmente expressa por afirmativas contingentes ("admitindo que os agentes econômicos têm expectativas racionais...”), são elaboradas versões mais simplificadas e normativas, através de outras instituições, como as organizações internacionais (veja-se o papel do Banco Mundial e do FMI), a mídia e a própria academia (através de manuais), que se expressam por indicadores empíricos (por exemplo, os de "boa governança" do Banco Mundial) e receituários de política, como o decálogo do Consenso de Washington. A integração internacional da academia e demais organizações difunde este conhecimento codificado nas sociedades específicas. A retórica atualmente adotada nas versões eruditas, em que "teoria" tornou-se sinônimo de "modelos formais", sujeitos a um tratamento matemático sofisticado, torna restrito o público que as entende e confere-lhes um caráter sagrado.

Outra parte dos conhecimentos codificados tem origem religiosa e em procedimentos de socialização, a exemplo de mitos, fábulas e cerimônias de iniciação, que são compartilhados pelos membros da população P. Estes conhecimentos, além de estabelecer laços comunitários, têm a função de reduzir a incerteza, mostrando como, cumpridas certas condições, é possível sair de situações "más" (o pecado, a inflação, a pobreza) e chegar a situações "boas" (a virtude, a estabilidade, a riqueza).

O conhecimento tácito refere-se às percepções não codificadas sobre como a sociedade "é" e como "deveria ser", compartilhadas pelos membros da população $P$, que resultam da experiência dos atores e que são transmitidas, dentro da mesma geração e entre gerações, através de vários mecanismos cul-

\footnotetext{
${ }^{2}$ Uma discussão mais detalhada do conteúdo cognitivo das convenções de desenvolvimento encontra-se em Erber (2008).
} 
turais e educacionais - por exemplo, provérbios como "manda quem pode, obedece quem tem juízo".

A "visão das coisas" a que se referia Schumpeter, que precede a codificação científica do conhecimento, é constituída por conhecimentos tácitos e conhecimentos codificados não científicos. Através de alguns destes conhecimentos, como os mitos, a "visão das coisas" ganha um componente teleológico. ${ }^{3}$

Os conhecimentos codificados tendem a se traduzir em regras formais de conduta, frequentemente dotadas de um poder coator externo - o Estado, ao passo que os conhecimentos tácitos são normalmente expressos por regras em que a força de coação reside na aprovação do grupo.

Embora os conhecimentos codificados tenham, forçosamente, que ser adaptados às condições locais para se transformarem em regras de conduta, é nos conhecimentos tácitos, que refletem a vivência dos atores quanto à sociedade, $\mathrm{e}$ na interação entre os dois tipos de conhecimento, que a especificidade local mais se manifesta, até pela ineficácia das regras formais (as leis que "não pegam").

Os conhecimentos tácitos e as regras informais de conduta são importantes na concepção e implementação das convenções de desenvolvimento, mas, atemo-nos aqui, por razões de espaço, aos conhecimentos codificados de base científica.

Uma convenção de desenvolvimento não se limita a um dispositivo cognitivo - para ser eficaz ela tende a se espraiar em outras instituições/regras, como leis e regulamentos e a inserir-se em organizações, como as burocracias públicas e privadas e a academia. Por gerar outras organizações e regras, é uma instituição constitucional. Este processo de difusão cumulativa assume características de auto-organização (De Wolf \& Holvoet, 2005), formando um sistema adaptativo em que a estrutura é mantida sem que seja necessário um controle externo. Em consequência, a convenção passa a ser vista como algo natural e externo aos seus aderentes.

Conforme já apontado, a legitimidade de uma convenção depende da congruência dos seus resultados com as expectativas da população $\boldsymbol{P}$. Se $\boldsymbol{P}$ é um grupo relevante dentro da estrutura de poder da sociedade, a legitimidade da ordem social da qual a convenção de desenvolvimento faz parte é reforçada.

No entanto, a natureza cumulativa do processo de constituição e difusão de uma convenção de desenvolvimento torna-a dependente em relação à trajetória que vinha sendo seguida. Assim, se surgem problemas distintos daqueles que a convenção identificou como prioritários e que demandam soluções não compatíveis com o núcleo duro da convenção, esta entra em crise e tende a ser substituída por outra convenção. Os episódios da dívida externa na América Latina

\footnotetext{
${ }^{3}$ Furtado (1974) discute o mito do Progresso para destacar a especificidade da trajetória dos países periféricos em comparação com os países capitalistas centrais. Erber (2002) analisa o papel do mito da Terra Prometida na configuração da convenção neoliberal.
} 
ou da derrocada do socialismo na Europa Oriental e a substituição do desenvolvimentismo e do socialismo pelo neoliberalismo ilustram bem este processo.

As convenções de desenvolvimento constituem, pois, dispositivos de identificação e solução de problemas. Embora sejam sempre apresentadas como "projetos nacionais" que levam ao "bem comum", refletem, na verdade a distribuição de poder econômico e político prevalecente na sociedade, num determinado período. Como o processo de desenvolvimento envolve mudanças estruturais, uma convenção eficaz deve oferecer escopo a grupos emergentes, que não pertencem ao bloco de poder, especialmente quando o regime político é democrático. No entanto, em sociedades complexas, em que existem diversos interesses conflitantes, nenhuma convenção de desenvolvimento consegue acomodar a todos. Assim, existem sempre diversas convenções de desenvolvimento que competem pela hegemonia.

Embora uma convenção que foi hegemônica durante um período possa deixar de sê-la, a perda de hegemonia não implica no seu desaparecimento - os grupos sociais a que servia de representação continuam presentes e ela está inserida em múltiplas instituições, cuja mudança é lenta. Assim, embora derrotada, ela segue competindo pela hegemonia, adequando-se à nova problemática.

A história brasileira ilustra bem a competição entre convenções. ${ }^{4}$ Mesmo quando o nacional-desenvolvimentismo foi hegemônico, os liberais não deixaram de apresentar uma convenção alternativa (Bielschowsky, 1982). Da mesma forma, são conhecidos os conflitos entre neodesenvolvimentistas e neoliberais, durante a hegemonia do liberalismo no período Cardoso, mesmo no seio do Governo (Sallum Jr. ,2000). Conforme detalhado a seguir, esta competição encontra-se no governo Lula.

\section{AS CONVENÇÕES DE DESENVOLVIMENTO NO GOVERNO LULA}

\section{A necessidade de uma nova convenção de desenvolvimento}

Todo começo de governo é incerto, mas, no início do primeiro mandato do Presidente Lula, a incerteza era extraordinária. Embora durante a campanha eleitoral de 2002 o candidato Lula tivesse abandonado a retórica radical de "ruptura com o modelo neoliberal" em favor de uma "transição lúcida", assegurando, na Carta aos Brasileiros, "o respeito aos contratos", pairavam sobre seu futuro governo as dúvidas decorrentes do seu passado, onde figurava inclusive a profissão de fé no socialismo (por mais indefinido que este fosse), o preconceito contra um ex-operário e a insistência dos oponentes, secundada pela mídia, sobre sua falta de preparo intelectual para o exercício da

\footnotetext{
${ }^{4}$ Ver Castro (1993) e Erber (2002) para análises, respectivamente, da antiga convenção desenvolvimentista e da convenção neoliberal.
} 
Presidência. Somava-se a estas dúvidas a brusca deterioração da economia no segundo semestre de 2002, quando a ação conjunta de vários atores econômicos, temerosos quanto aos resultados das eleições e visando estabelecer condições de barganha vantajosas, produziu brusca elevação da taxa de inflação, desvalorização da taxa de câmbio e redução da taxa de crescimento. Para completar, as cores do quadro internacional eram sombrias: ainda se faziam sentir os efeitos das crises da Argentina e das empresas de energia e tecnologia de informação e uma nova guerra no Golfo era iminente.

Respondendo à incerteza, o discurso de posse de Lula no Congresso, reiterou sua convicção de que o antigo modelo estava esgotado e que "mudança" era a palavra-chave, mesmo que esta devesse ser gradual, perseguida com paciência e perseverança. Para tanto, eram necessários um "projeto nacional de desenvolvimento", apoiado num "planejamento estratégico".

Tal projeto seria dirigido principalmente para as necessidades dos pobres — empregos, educação, saúde e, especialmente, alimentação. Para atingir estes objetivos, Lula enfatizou a necessidade de estabilidade macroeconômica, principalmente a administração responsável das finanças públicas. O crescimento resultaria de um aumento das poupanças e investimentos, com foco no mercado interno, principalmente nas pequenas e médias empresas, infraestrutura e capacidade tecnológica. Uma ampla gama de reformas institucionais era prevista, nos campos fiscal, previdenciário, agrário, da legislação trabalhista e político. Para realizar este ambicioso programa, seria necessário um novo "pacto social", unindo trabalho e capital produtivo, de forma a gerar uma "energia solidária".

Pode-se interpretar tal discurso como o reconhecimento da necessidade de uma nova "convenção de desenvolvimento", ratificada pelo recuo da convenção neoliberal, tanto no plano internacional como no Brasil. O apelo a um "pacto social amplo" também era consistente com o "presidencialismo de coalizão" que caracteriza o sistema político brasileiro e que obriga o Presidente a realizar coalizões com forças que não sustentaram a sua candidatura e que têm objetivos programáticos (quando os têm) distintos.

$\mathrm{Na}$ verdade, a necessidade de uma nova convenção, de natureza mais inclusiva do ponto de vista econômico e social, foi interpretada, no âmbito do Governo, de forma diferenciada, gerando duas convenções distintas, tratadas, a seguir, a partir de documentos programáticos governamentais.

Antes, porém, cabe registrar uma ironia da História. Ao governo Cardoso, que apostou todas as suas fichas no comportamento favorável do mercado externo, coube um período de grande conturbação deste mercado - da crise mexicana à argentina, passando pela nossa. Ao contrário, o governo Lula, que iniciou sob o consenso de restrições externas, foi beneficiado, entre meados de 2003 e a crise de 2008, por uma enorme expansão do comércio e da liquidez internacionais, concentrado o primeiro em commodities primárias e produtos semielaborados, o Brasil conta com inequívocas vantagens comparativas. 
A convenção institucionalista, tal como apresentada pelo Ministério da Fazenda e pelo Banco Central, tem uma visão de sociedade competitiva e meritocrática, cuja eficiência é garantida pelo funcionamento do mercado.

Seu cerne analítico é neoclássico, enriquecido pelos aportes da Nova Economia Institucional (North, 1990). Visa ao estabelecimento de normas e organizações que garantam o correto funcionamento dos mercados, de forma que estes cumpram suas funções de alocar recursos do modo mais produtivo, gerando poupanças, investimento e, em consequência, crescimento econômico. Quanto mais eficientes forem os mercados em termos presentes e futuros, maior será a probabilidade de crescimento. Para tanto, são essenciais a garantia dos direitos de propriedade e a redução dos custos de transação, que, por sua vez, demandam instituições estatais eficientes. Os mercados têm dimensão internacional e, portanto, a abertura da economia, em termos comerciais, financeiros e de investimento é essencial para o desenvolvimento.

A inovação, tecnológica e institucional, é vista como o motor do desenvolvimento e a abertura internacional desempenha um importante papel no seu estímulo através da importação de tecnologias mais produtivas, incorporadas em bens de capital e insumos.

Como o mercado de conhecimentos é inerentemente imperfeito, a intervenção do Estado é neste campo, necessária, assim como em atividades em que existem "monopólios naturais".

Dada a conhecida carência brasileira em inovação e infraestrutura, o Estado deveria ter um papel ativo no seu fomento. Para esta última havia, no Ministério da Fazenda, uma clara preferência pelo modelo principal-agente, no qual o Governo (o principal) fixa as diretrizes de política e a Agência, apoiada em regras estáveis e transparentes de gestão, executa tais diretrizes e presta contas ao principal por sua execução. Este modelo, destinado a evitar as ineficiências do suprimento direto de serviços por instituições estatais e, ao mesmo tempo, reduzir os riscos de "captura" das agencias pelos seus regulados, havia sido adotado no Brasil nos setores privatizados (com variados graus de sucesso) e, conforme discutido a seguir, para a execução do regime de metas inflacionárias pelo Banco Central.

A adesão do governo Lula a esse modelo organizacional foi muito parcial. As relações governo-agências setoriais têm sido marcadas por fortes conflitos. A exceção corre pelo caso do Banco Central, visto a seguir.

Reconhecida a prioridade a ser dada a uma distribuição de renda mais equitativa, inclusive para os objetivos de maior crescimento, recomendava-se não só o investimento em capital humano através da educação, como políticas "focalizadas" nos "pobres". A "focalização", que seguia o cânone estabelecido por instituições internacionais como o Banco Mundial, encontrava apoio no diagnóstico de que os gastos sociais feitos pelo Estado brasileiro eram significativos - o problema estava na sua ineficácia, posto que parte substancial 
destes gastos estaria dirigida aos "não pobres". A solução, pois, era a "focalização" nos "pobres" através de mecanismos institucionais eficientes e eficazes, mesmo que tal orientação estivesse em oposição ao "universalismo" defendido pelo PT. O Bolsa Família viria a concretizar a focalização.

A estabilidade de preços e a expectativa dos atores econômicos de que esta é duradoura constituem parte indispensável desta convenção, posto que afetam não apenas as transações correntes como os contratos futuros e, portanto, a poupança e o investimento. Ao mesmo tempo, afeta positivamente a equidade, posto que os "pobres" tendem a ser mais afetados pela alta inflação.

O cânone liberal condiciona a estabilidade ao estabelecimento de regras formais que disciplinem o comportamento do Governo e dos agentes privados. Tais regras se expressam através de metas, fiscais e de inflação, que permitem à sociedade monitorar o desempenho do Governo. Implícita, está a crença na tendência do Governo em incorrer num "viés inflacionário", mas os agentes privados também necessitam ser disciplinados, cabendo à política monetária do Banco Central o papel central na "ancoragem" das expectativas, através de metas inflacionárias, e à flexibilidade da taxa de câmbio a correta adequação da economia às condições internacionais.

Ao iniciar-se o primeiro mandato do Presidente Lula, o Ministério da Fazenda (2003) anunciou que "o novo governo tem como primeiro compromisso da política econômica a resolução dos graves problemas fiscais que caracterizam nossa história econômica, ou seja, a promoção de um ajuste definitivo das contas públicas" (p. 8, ênfase original). No mesmo sentido de estabilização, deveria ser dada prioridade à reforma da Previdência, conferida autonomia legal ao Banco Central e reforçados os direitos de credores, o que, em tese, conduziria a uma redução dos prêmios de risco e, portanto, à redução da taxa de juros.

"Reforma fiscal" é um bordão de todo Ministro da Fazenda a partir da agonia do Estado desenvolvimentista nos anos 1980 e constitui um tema que, em termos gerais evoca consenso, mas que, quando busca-se implementá-lo, esbarra em interesses incontornáveis e irreconciliáveis, à semelhança das reformas administrativa e política. O governo Lula seguiu as linhas de menor resistência, aumentando a carga tributária, sem deixar de enviar ao Congresso a ritual proposta de reforma, que se encontra "em discussão". Para a Previdência, feita uma pequena reforma, o tema foi abandonado.

Quanto às reformas dirigidas ao sistema monetário e financeiro, o Banco Central não ganhou sua independência legal, mas seu Presidente foi alçado ao status ministerial e a organização reteve sua capacidade de estabelecer objetivos e sua forte autonomia operacional para implementá-los (veja-se a seguir). Os direitos dos credores foram reforçados (p.ex. via Lei de Falências), mas os efeitos da sua maior segurança sobre as taxas de juros são difíceis de discernir.

O silêncio é tão eloquente como a fala. Embora privilegiasse a eficiência institucional, o documento da Fazenda omitia-se quanto a mudanças institucionais de caráter estrutural, como a reforma administrativa do Estado e a 
reforma política, apesar dos inequívocos efeitos destas sobre a eficiência dos mercados e do próprio Estado. A trajetória histórica manifestava seu peso.

Do ponto de vista cognitivo, as reformas institucionais propostas eram derivadas da convenção liberal e faziam parte da "segunda geração" de reformas do Consenso de Washington, dando continuidade ao processo iniciado na década de 1990. Não obstante, apontavam para problemas estruturais, como a reforma fiscal e o equacionamento financeiro da Previdência. A solução destes problemas não necessita ser feita segundo as propostas liberais — soluções alternativas podem ser encontradas, desde que a importância dos problemas seja reconhecida e as alternativas resolvidas politicamente. A minimização do debate e o adiamento das soluções, apontam para uma preferência pelo curto prazo e para as dificuldades inerentes à governança no "presidencialismo de coalizão". A mesma conjectura aplica-se às reformas omitidas.

Concebida de forma restrita e implementada parcialmente, a agenda institucionalista acabou por restringir sua prioridade à estabilização de preços, deixando o Banco Central no epicentro da política macroeconômica. Esta configuração não é nova - remonta aos anos 1980, em que o principal instrumento para impedir a eclosão da hiperinflação foi a alta taxa de juros paga por títulos da dívida pública, transformados em quase moeda. A centralidade do BACEN foi mantida no governo Collor e ampliada no primeiro mandato do Presidente Cardoso, quando o Banco estabeleceu a ancoragem cambial, a despeito da oposição de parte da equipe econômica. Apesar de ter conduzido o país à anunciada crise de 1999, o BACEN ressurgiu das cinzas sob o regime de metas de inflação, com poderes ampliados.

No Brasil, as metas de inflação são definidas pelo Conselho Monetário Nacional. As atas do Conselho, que poderiam indicar quais os critérios usados para sua definição, não são divulgadas, mas pode-se supor que, à semelhança do Federal Reserve Board, envolvam "ciência e arte" (Bernanke, 2007). Dado o traumático passado inflacionário brasileiro e os efeitos deletérios da inflação sobre os rendimentos das camadas mais pobres da população, que compõem o grosso do eleitorado, há uma compreensível relutância política do Governo em mostrar-se leniente com a inflação, o que torna a definição de metas dependente da sua evolução anterior. $\mathrm{Na}$ avaliação de executivos do Banco Central (Bevilaqua et al., 2007), a estabilidade de preços está associada a uma taxa de inflação inferior a $5 \%$ anuais.

No regime de metas de inflação em que o Banco Central tem, nominalmente, apenas autonomia operacional, o Banco recebe as metas de uma autoridade e tem a incumbência de executá-las, seguindo normas de transparência e de prestação de contas - um arranjo institucional do tipo principal-agente. No caso brasileiro, a separação entre fixação e execução (principal e agente) de metas é muito parcial, posto que o Presidente do Banco Central tem assento no Conselho Monetário Nacional, ao lado dos Ministros da Fazenda e Planejamento, e sua opinião, lá, pesa, e muito.

Cabe, ainda, insistir sobre dois pontos. Primeiro, o centro da meta infla- 
cionária e a banda de variação são o resultado de uma decisão política. A dependência em relação à trajetória passada não impede que, face a mudanças bruscas de cenário ou a objetivos eventualmente conflitantes com a manutenção do centro da banda, este ou os seus limites sejam alargados pelo CMN. $\mathrm{Na}$ verdade, o próprio BACEN pode fazê-lo, como já o fez em janeiro de 2003, quando "ajustou" o centro da meta em função da crise do segundo semestre do ano anterior, e em setembro de 2004, a título de acomodação à inércia inflacionária (Bevilaqua et al., 2007). Em segundo lugar, como testemunha o insuspeito Bernanke (2007), por mais sofisticados que sejam os modelos de previsão, há uma necessária dose de discrição nessas previsões.

Conforme explicado por seus executivos, o BACEN "guia suas decisões de política [para atingir as metas] por suas próprias previsões de inflação e dos respectivos balanços de riscos. As expectativas de inflação do mercado são insumos importantes nos modelos de previsão do BACEN... e são influenciadas pelo comportamento passado da inflação, as metas de inflação, o desenvolvimento da taxa de câmbio e do preço das commodities, a atividade econômica e o posicionamento da política monetária" (Bevilaqua et al., 2007, p. 5). Embora acreditem que o peso do passado na definição de expectativas tenha diminuído, atestando o sucesso da política de metas, constatam que, "muitas vezes, as expectativas apresentaram reações excessivas a eventos correntes, especialmente a surpresas inflacionárias... Neste sentido, o processo de desinflação tem sido, e ainda é, um processo de domar as expectativas inflacionárias" (ibid., p. 5) e "os custos de curto prazo, em termos de atividade econômica perdida, devem ser vistos como um investimento em estabilidade" (ibid., p. 13, ênfase adicionada).

Ao longo deste processo de disciplinar o mercado, o BACEN é rápido na elevação das taxas de juros e lento na sua redução (Modenesi, 2008) e pratica taxas de juros que, apesar de oscilarem, estão sempre entre as mais altas do mundo. Nesta operação, condiciona as outras duas pontas do tripé de políticas macro.

Do lado cambial, a entrada de capitais estrangeiros, atraída pelo diferencial de juros, valoriza o Real e contém o preço dos bens e serviços comercializáveis internacionalmente. Instrumentos financeiros como swaps cambiais reversos adicionam importantes aliados à política de manter a Selic elevada e a taxa de câmbio valorizada.

Do lado fiscal, obriga a política a estabelecer suas metas em termos primários, comprimindo gastos, notadamente de investimento, de forma a liberar recursos para o pagamento de juros sobre a dívida pública (não incluídos no resultado primário). A valorização do real e a liquidez do mercado internacional permitiram a acumulação de reservas cambiais e que o Tesouro eliminasse a sua dívida externa. Estas reservas foram um importante instrumento de defesa da economia durante a crise de 2008. No entanto, dado o diferencial en- 
tre os juros internos e externos, as reservas têm um importante "custo de carregamento", que é contabilizado no déficit nominal do setor público. ${ }^{5}$

Argumenta-se com frequência que a estabilidade de preços tem a natureza de um bem público, no sentido de que ninguém pode ser excluído de seus benefícios. No entanto, a política acima resumida tem distintos perdedores e ganhadores.

Entre os perdedores, os devedores encimam a lista. Entre estes, destaca-se o Estado, que pagou, em média, cerca de $6 \%$ do PIB ao ano à conta de juros no período 2003-2008, aproximadamente dez vezes o gasto no programa Bolsa Família. Dado que a tributação no Brasil é notoriamente regressiva, resulta uma maciça transferência de renda dos pobres para os ricos.

Há também perdedores no setor privado - todos os que necessitam utilizar mecanismos de crédito, dos consumidores que desejam adquirir ativos familiares a empresas que precisam financiar o seu capital de giro e investimentos.

Em consequência, a demanda final de bens de consumo é contida, com reflexos sobre toda a cadeia produtiva e os investimentos. O curto prazo da política monetária e o poder discricionário do BACEN aumentam a incerteza e o alto rendimento, grande liquidez e baixo risco das aplicações financeiras elevam a taxa mínima de retorno (burdle rate) dos investimentos produtivos. Assim, o portfolio de investimentos produtivos das empresas tende a se concentrar em projetos de curto prazo e baixo risco, exceto quando o mercado em expansão e a concorrência obrigam as empresas a investir, como foi, no período 2003-2007, o caso das atividades exportadoras de produtos primários e semielaborados.

As aplicações dos grandes gestores de recursos financeiros, como os fundos de pensão sofrem o mesmo viés e o sistema financeiro é encorajado a concentrar suas operações em títulos públicos, em detrimento da concessão de crédito, que tende a priorizar operações de curto prazo e baixo risco. Em consequência, o sistema privado de financiamento torna-se pouco funcional para as transformações estruturais típicas do desenvolvimento, deixando este papel a cargo dos bancos públicos.

Atividades cruciais para o desenvolvimento, como a inovação, notadamente projetos mais criativos, são desestimuladas, a taxa de crescimento do emprego diminui e o crescimento e a igualdade também. $\mathrm{O}$ "investimento em estabilidade" tem altos custos.

Do outro lado da lista, entre os ganhadores, destaca-se, primum inter pares, o sistema financeiro. O balanço consolidado dos bancos brasileiros mostra que o volume de lucros líquidos triplicou entre 2003 e 2007 e que a sua taxa de lucro passou de 14,8\% em 2003 para 22,9\% em 2007 (Valor Econômico, 2008). No entanto, o sistema financeiro não está só. Investidores institucionais

\footnotetext{
${ }^{5}$ Perdas ou ganhos com a variação cambial são contabilizados como ajuste patrimonial na dívida interna líquida (Safatle, 2009).
} 
como fundos de pensão, companhias de seguro, empresas com alta geração de caixa (empresas industriais produtoras de bens intermediários, produtores e vendedores de commodities agrícolas, atacadistas, cadeias de lojas de bens de consumo) também se beneficiam, assim como os domicílios mais ricos, notadamente os que pertencem ao $1 \%$ superior da pirâmide de distribuição de renda e recebem cerca $13 \%$ da renda total do país. Os dados de Bruno (2007) indicam que as empresas não financeiras e indivíduos receberam, na média, cerca de $80 \%$ das rendas financeiras durante o período 1995-2005.

A valorização do câmbio é irmã siamesa dos altos juros. Os exportadores e os produtores locais de bens comercializáveis são os principais prejudicados pela valorização. No entanto, entre os primeiros, os que exportam commodities, sejam produtos primários ou semielaborados, foram, a partir de 2003, parcialmente compensados pelo aumento dos preços no mercado internacional e, sendo grandes geradores de caixa, pelos altos juros locais. Em contrapartida, os importadores de bens e serviços beneficiam-se muito com a valorização do câmbio, de tal forma que, apesar das condições favoráveis para as exportações brasileiras, o saldo em transações correntes, que havia chegado a quase $2 \%$ do PIB em 2004, foi praticamente nulo em 2007 e negativo a seguir. Vistas pelo ângulo da conta de capitais, as duas irmãs atuam no sentido de favorecer as empresas que têm condições de aceder ao crédito externo e a todos a quem convém remeter recursos para o exterior, seja para investimentos (principalmente os produtores de commodities), seja a título de juros, lucros e dividendos, cujo montante mais do que dobrou entre 2003 e 2008.

Existe, pois, uma ampla e poderosa constelação de interesses, estruturada ao longo do tempo em torno à combinatória altos juros-câmbio valorizado, que estabeleceu uma convenção que estes elementos são essenciais para o desenvolvimento do país. A política do Banco Central atende estes interesses e minimiza os riscos de ocorrência de episódios de turbulência, como os ocorridos no segundo semestre de 2002.

Argumentos como o "pecado original" da moratória de 1987, a "incerteza jurídica" dos credores e o crédito "não livre" ou o déficit público são oferecidos como justificativa. Fatos como as taxas de juros muito mais baixas que as brasileiras em países que também entraram em moratória, como o México, a concessão de "grau de investimento" por agências internacionais de avaliação de risco, que deveria ter redimido o pecado, o reforço das garantias dos credores, acima mencionado, a falta de disposição do sistema financeiro privado para o crédito agrícola e de longo prazo e o bom desempenho fiscal do Governo são convenientemente omitidos.

Esta coalizão de interesses tem poderosos instrumentos para consolidar e difundir sua convenção de desenvolvimento. O mais explícito está nas mãos do sistema financeiro, como demonstrado na crise do segundo semestre de 2002, que tão efetivamente domou as expectativas do governo entrante. Mas há outros instrumentos, mais sutis, como o financiamento de campanhas 
políticas, ${ }^{6}$ as relações com os membros do Congresso, os "anéis burocrático-empresariais" de que, no passado, falava Cardoso, o sociólogo, e as relações com a mídia, que difunde a convenção de estabilidade.

O Banco Central é um membro necessário desta coalizão — é a instituição que concebe e executa a política monetária, com os efeitos já apontados sobre a política cambial e fiscal e a distribuição de rendas. A autonomia do BACEN reflete a força da coalizão e, ao mesmo tempo, dadas as características já apontadas da política que pratica, reforça o peso econômico e político da coalizão, num processo cumulativo - sem que isto implique, necessariamente, uma "captura" do Banco pelo sistema financeiro no sentido da "escolha pública". Para o estabelecimento da coalizão e da convenção que lhe serve de representação social, basta que o Banco Central e os membros privados derivem benefícios conjuntos da mesma política - no caso, o prestígio de cumprir as metas e os lucros derivados dos altos juros e do câmbio valorizado.

Além de objetivos comuns, diversos mecanismos reforçam a coesão desta coalizão e a força da convenção a ela vinculada.

A atual estrutura do sistema financeiro brasileiro foi muito influenciada pela crise bancária de 1995 e pela privatização dos bancos estaduais, processos em que o Banco Central teve um papel decisivo, participando da gênese ou desenvolvimento dos grandes grupos privados que dominam o sistema. A mesma crise levou ao aprofundamento das atividades de supervisão do sistema financeiro exercidas pelo Banco Central (p.ex. a aplicação das regras de Basileia), estreitando os laços entre as partes. Como toda agência reguladora, o Banco Central tem que manter contato estreito e contínuo, formal e informal, com os atores regulados, formando uma percepção comum dos problemas e soluções. A execução da política monetária aumenta a integração: as estimativas de inflação feitas pelo sistema financeiro (que tem implícito um viés favorável ao aumento de juros) constituem um importante insumo para as estimativas do Banco Central e as reuniões do COPOM onde a taxa de juros básica é definida têm periodicidade fixa e são precedidas de incontáveis manifestações de representantes do sistema financeiro sobre a decisão do Comitê. Finalmente, o horizonte com que as metas são estabelecidas pelo Conselho Monetário - um ano e meio adiante — facilita a convergência entre o BACEN e o sistema financeiro.

No plano cognitivo, a convenção se expressa na crença, partilhada pelos membros da coalizão que a sustenta, na eficácia e legitimidade do mercado como a principal instituição encarregada de organizar e conduzir a economia e a sociedade através de uma distribuição eficiente no uso de recursos. Tal crença valida o uso da força da coalizão para ampliar a gama de relações sociais regidas pelo mercado (a exemplo da saúde, previdência e educação) e

\footnotetext{
${ }^{6}$ Veja-se Filgueiras \& Gonçalves (2007) para as contribuições do sistema financeiro às campanhas das eleições presidenciais de 2002 e 2006.
} 
vetar projetos e políticas que possam reduzir o poder do mercado em favor de outras instituições. Implícita nestas duas agendas - positiva e negativa - está a tese neoliberal de que, mesmo que o mercado não se coadune ao ideal concorrencial, as falhas introduzidas no processo de alocação eficiente de recursos pela ação de outras instituições, notadamente o Estado, são ainda maiores. Neste sentido, a crise não resolvida do Estado desenvolvimentista, manifesta nos aspectos político, fiscal e administrativo, joga a favor da convenção.

Um viés conservador une ainda mais o Banco Central e os interesses privados - o primeiro quer manter a estabilidade de preços, os segundos o rentável status quo, consolidado ao longo dos anos. Ambos se opõem a mudanças estruturais que alterem a distribuição de riqueza e renda e preços relativos, aumentando o risco de inflação. Em consequência, a coalizão usa seu poder não apenas para promover políticas que a beneficiem, mas também para obstar políticas que alterem o status quo.

Denominamos, inicialmente, a convenção acima descrita como sendo institucionalmente "restrita". No entanto, conforme a análise acima aponta, o adjetivo pode também ser aplicado à gama de mudanças estruturais que tal convenção propugna. Se desenvolvimento é mudança estrutural, trata-se, na melhor das hipóteses de um "desenvolvimento restrito".

\section{A convenção neo-desenvolvimentista}

Coexistindo com a convenção acima descrita, mas a ela subordinada, há outra, a que podemos chamar de "neodesenvolvimentista". À diferença da convenção institucionalista, esta tem uma visão de sociedade essencialmente cooperativa, expressa através do conceito de "pacto social" e das metáforas usadas pelo Presidente da República, que assemelham a sociedade a uma família ou a uma equipe esportiva, que se traduz, na prática, na prioridade à inclusão social.

Do ponto de vista econômico, seu núcleo duro é de inspiração keynesiana - o crescimento é impulsionado pelo aumento autônomo da renda familiar dos grupos mais "pobres", via salário mínimo e transferências fiscais, e de investimentos em infraestrutura e construção residencial, regidos pelo Estado. No entanto, distingue-se da convenção "novo-desenvolvimentista", que tem a mesma matriz teórica (ver quarta seção), pela aceitação, mesmo que a contragosto, da política macroeconômica da convenção institucionalista restrita, que os "novo-desenvolvimentistas" explicita e fortemente rejeitam.

Proposta inicialmente no Plano Plurianual de Aplicações (PPA) 2003-2007, ampliada pela Política Industrial, Tecnológica e de Comércio Exterior (PITCE) e pela tentativa de estabelecer parcerias público-privadas, em 2003, a convenção neodesenvolvimentista foi reforçada, a partir de 2006, pela mudança de equipe no Ministério da Fazenda e pela reeleição do Presidente Lula. Encontra sua forma atual no Programa de Aceleração do Crescimento 2007-2010 (PAC) e na recente Política de Desenvolvimento Produtivo (PDP). 
A convenção repousa sobre cinco pilares, que justificam a denominação dada:

- Investimento em infraestrutura (principalmente energia, logística e saneamento), a ser feito majoritariamente por empresas estatais e privadas, com o financiamento do BNDES e, em menor grau, diretamente pelo Estado. Parte destes investimentos responde a carências há muito identificadas e podem ser vistos como a "recuperação do atraso". No entanto, a descoberta de grandes jazidas de petróleo em águas muito profundas (o pré-sal) abre a perspectiva de enormes investimentos nesta área e, a seguir, da remoção da restrição de divisas pela exportação de petróleo e seus derivados. Para tanto, porém, será necessário equacionar adequadamente as condições institucionais que regerão a exploração desta área e o esquema de financiamento para os referidos investimentos, que, na sua maior parte, serão realizados após a conclusão do PAC atual.

- Investimento residencial incentivado pelo crédito, público e privado, amparado por maiores garantias dos credores. Buscava-se aqui também reduzir o enorme déficit habitacional do país (estimado em 6 milhões de residências) e da baixa participação do crédito para este fim no PIB (menos de $2 \%$ ).

- círculo virtuoso entre, de um lado, o aumento de consumo das famílias derivado dos aumentos do salário mínimo, das transferências do Bolsa Família, da expansão do emprego formal ${ }^{7}$ e do crédito $^{8}-\mathrm{e}$, do outro lado, o aumento do investimento em capital fixo e inovação, incentivado pela desoneração fiscal e pelo crédito dos bancos públicos.

- Investimento em inovação, amparado por incentivos fiscais, crédito subsidiado e subvenções.

- Política externa independente, que privilegia as relações com outros países em desenvolvimento (seja da América Latina, seja do grupo BRIC) e busca afirmar o papel do Brasil como protagonista do processo de mudanças na arquitetura institucional mundial.

O Estado, nesta convenção, volta a assumir um papel de liderança no processo de desenvolvimento, recuperando, inclusive, o protagonismo das empresas estatais e dos bancos públicos, perdido durante o período liberal.

Nos dois primeiros pilares e no último, é clara uma atualização da antiga proposta desenvolvimentista. Restabelece-se a tradicional coalizão entre empreiteiras da construção pesada e leve, fornecedores de insumos e equipamentos e seus empregados com o governo.

A capacidade local de inovação (o quarto pilar), buscada pelo desenvolvi-

\footnotetext{
${ }^{7}$ Estimulado por medidas como o tratamento tributário simplificado para pequenas empresas e maior fiscalização.

${ }^{8}$ Ver quarta seção.
} 
mentismo dos anos 1970, é, hoje, objeto de um consenso que abarca todas as correntes de pensamento, contando com forte apoio do Banco Mundial. A PITCE de 2003 tinha um forte componente heterodoxo em sua agenda positiva, ao estabelecer claras prioridades setoriais e tecnológicas ${ }^{9}$, em função de encadeamentos tecnológicos e dos déficits no comercio internacional. Esta heterodoxia foi atenuada em favor de políticas "horizontais", possivelmente devido à redução da restrição externa. Também, à diferença do período desenvolvimentista, na agenda atual não se distinguem os detentores da capacidade de inovação pela origem do seu capital, apesar dos efeitos desta diferença sobre a competitividade internacional e a soberania nacional.

Cabe destacar que, à diferença da antiga convenção desenvolvimentista e da convenção neoliberal, o governo Lula, colocou no topo de sua agenda, através dos mecanismos apontados no que é descrito acima como o terceiro pilar neodesenvolvimentista, a redução da pobreza, herdada do longo período em que as duas convenções foram hegemônicas. A agenda atual almeja o consumo de massas e seu investimento derivado, mas também sanar a restrita inclusão econômica, há muito apontada como óbice principal à sustentabilidade do desenvolvimento (Furtado, 1961).

Do ponto de vista político, a forma como a política de inclusão foi implementada, de outorga de um benefício pelo Estado, é consistente com trajetória de um Estado paternalista que remonta ao varguismo ${ }^{10}$ e tem como efeito colateral a perda de importância das organizações da sociedade civil, notadamente as que representam os "pobres" e o aumento da importância dos poderes locais, responsáveis pela inclusão dos "pobres" nos programas de assistência. A redução dos conflitos sociais, inerente à política e sua forma de implementação, inclusive pelo baixo custo fiscal que envolve, é de interesse também dos grupos de maior renda, estabelecendo uma ponte entre as duas convenções.

A inclusão se dá via aumento de renda - não contempla a redistribuição de riqueza. Os detentores desta última (notadamente a financeira), fortemente beneficiados pelas políticas da convenção de estabilização, têm seus interesses preservados. Dada a regressividade da estrutura fiscal, na medida em que a inclusão é financiada via gastos fiscais são os "pobres" que arcam com parcela maior do seu custo. Neste sentido, os "pobres" são as vítimas principais dos impasses que cercam a reforma fiscal do Estado brasileiro.

O principal ativo desenvolvido pela política de inclusão é o da educação,

\footnotetext{
${ }^{9}$ Bens de capital, componentes eletrônicos, software e fármacos constituíam os setores prioritários. A estes se adicionavam tecnologias novas, de uso difundido, "portadoras de futuro" - biotecnologia, nanotecnologia e biocombustíveis.

${ }^{10}$ A tradição varguista encontra-se também na composição corporativa de instituições destinadas a formular políticas públicas, como a industrial e tecnológica, onde estão representados, além do Estado, "trabalhadores" e "empresários".
} 
através da condicionalidade das transferências à presença das crianças das famílias beneficiadas nas escolas - um efeito intergeracional. Aos adultos, a política oferece poucas “portas de saída”, entre as quais destaca-se a expansão do emprego de baixa qualificação.

Este efeito intergeracional é, infelizmente, mitigado pela má qualidade do ensino público. A esta lacuna somam-se outras deficiências no atendimento dos serviços básicos, de responsabilidade do Estado, como saúde, transporte público, segurança pessoal e acesso à proteção legal, que incidem principalmente sobre os "pobres".

O lento progresso nessas áreas, historicamente carentes, enfrenta inúmeros obstáculos institucionais. Aumentar os gastos públicos nestas áreas esbarra, de um lado, na resistência política ao aumento da carga tributária e, de outro, nas metas de superávit primário, estipuladas pela convenção de estabilização. Reformas dos sistemas de governança desses serviços públicos, incluindo as atribuições de responsabilidade, estabelecimento de metas e procedimentos de monitoramento e avaliação, esbarram em interesses particularistas fortemente constituídos (por exemplo, as empresas privadas de transporte público e sua projeção política nos governos municipais) e na representação dos "pobres" por políticos que privilegiam medidas de curto alcance, de natureza clientelística. ${ }^{11}$ Desta forma, uma vez mais, são os "pobres" os principais perdedores da ausência das reformas (fiscal e administrativa) do Estado brasileiro.

Em síntese, a convenção desenvolvimentista do governo Lula também reúne um conjunto de relevantes interesses, econômicos e políticos, embora sua dimensão "inclusiva" também seja restrita. Não obstante, é importante destacar que a prioridade dada aos "pobres", manifesta na redução dos índices de pobreza e desigualdade, constitui uma modificação crucial na agenda positiva de desenvolvimento que, dado o seu impacto político, tende a se manter.

\section{A coexistência entre as duas convenções}

Conforme apontado acima, as duas convenções têm "visões das coisas" e "núcleos duros" distintos e atendem interesses diferentes. Tais diferenças se traduzem nas prioridades de modificação estrutural postuladas pelas duas convenções e em agendas de políticas distintas.

As diferenças nas agendas se expressam de forma clara nas políticas atinentes aos investimentos e à taxa de câmbio.

\footnotetext{
${ }^{11} \mathrm{O}$ contraste entre as duas "áreas de atraso" — infraestrutura econômica e serviços sociais —é ilustrativo da importância de coalizões organizadas em torno a objetivos específicos. No primeiro caso, existem projetos, com objetivos e recursos definidos (construir uma hidroelétrica, pavimentar uma estrada), cujos beneficiários imediatos (os construtores) são poucos e dotados de recursos organizativos e políticos. No segundo caso, os objetivos são de longo prazo, com indicadores de sucesso limitados e seus beneficiários são dispersos e desprovidos de recursos eficazes.
} 
À primeira vista, ambas as convenções compartilham o desejo de ampliar os investimentos, notoriamente baixos no Brasil.

Para a neodesenvolvimentista, esta é a mola do crescimento e, para tanto, segue, para os investimentos privados, uma estratégia de "pinça": de um lado amplia o mercado, via consumo familiar e governamental e pelos encadeamentos do investimento público autônomo, e de outro, concede estímulos fiscais e de crédito, via bancos públicos, que reduzem o custo do investimento. Ao mesmo tempo vem ampliando os investimentos públicos, notadamente em infraestrutura e energia. Os diferentes prazos de maturação destas medidas implicam a forte probabilidade de ocorrerem descompassos temporários entre oferta e demanda em mercados específicos, que, num regime de metas de inflação, podem ser acomodados na margem de variação em torno do centro da meta. A previsibilidade das taxas de juros e câmbio, baixa taxa de juros e taxa de câmbio que mantenha as atividades locais competitivas internacionalmente, constituem ingredientes básicos de uma agenda de estímulo ao investimento.

Para o BACEN, o aumento da capacidade de oferta é essencial para um cenário "benigno" para a inflação futura, evitando que a demanda exerça pressões sobre o nível de preços. O Banco não divulga suas estimativas de hiato de produto, mas Barbosa (2009) argumenta que os estudos do BACEN sobre o hiato utilizam procedimentos que, num contexto de aceleração do investimento, tem um viés conservador.

Dado o poder do BACEN de afetar o crescimento, a ampliação da taxa de investimento torna-se essencial não apenas no plano "real" como no simbólico, reduzindo a probabilidade de interrupções no processo de crescimento impostas pelo Banco, para o qual os "custos de curto prazo, em termos de atividade econômica perdida, devem ser vistos como um investimento em estabilidade" (Bevilaqua et al., 2007, p. 13). Ao investimento em estabilidade seguir-se-ia, algum dia, o investimento em capacidade produtiva. Conforme apontado acima, ao contrair a demanda via aumento da taxa de juros, o BACEN afeta negativamente, de forma direta e indireta, o investimento produtivo.

A hierarquia de prioridades é, pois, distinta entre as duas convenções. A história recente mostra claramente não apenas as preferências como o poder do BACEN.

Assim, o temor da pressão de demanda foi um dos principais determinantes da elevação da taxa de juros em setembro de 2004 (alta que durou um ano), visando reduzir o crescimento do PIB, que vinha evoluindo a taxas de cerca de $6 \%$ nos trimestres anteriores (ibid.). Como resultado, a taxa de crescimento do PIB caiu de 5,7\% em 2004 para 3,2\% em 2005.

Em 2008, o BACEN deu outras demonstrações de poder e conservadorismo. Embora o aumento da inflação no primeiro trimestre fosse atribuível aos preços internacionais, o Banco a atribuiu à pressão da demanda interna sobre a capacidade produtiva e, estimando que havia um forte risco da inflação ficar acima do centro da meta (embora dentro da margem de variação de $2 \%$ ), deu início, em abril, a um novo - e forte - ciclo de elevação da taxa básica de 
juros, que passou de $11,25 \%$ ao ano em março para $13,75 \%$ em setembro. Em outubro, mais de um mês após a crise internacional tornar-se virulenta, o COPOM continuava preocupado com os riscos "para um cenário menos benigno" de inflação, postos pelo descompasso entre os aumentos de demanda e oferta (Ata da Reunião 138). À diferença dos seus pares no mundo, tanto de países desenvolvidos como emergentes, o Banco Central manteve a taxa de juros no seu nível elevado, quando a crise de liquidez e as condições fiscais sugeriam a conveniência de reduzi-la. Mais, o COPOM acenava claramente com a elevação da taxa de juros se as expectativas de inflação não convergissem para o centro da meta (ibid). Assim, à incerteza para a produção e investimentos, decorrente da situação internacional, somava-se a produzida pelo BACEN. Com a retração do crescimento do PIB no último trimestre do ano, o BACEN, além de adotar medidas de ampliação da liquidez, cortou a Selic, chegando a $8,75 \%$ em agosto de 2009 , quando deu fim às reduções. Embora o investimento tenha apresentado forte contração em 2009, há consenso que o BACEN voltará aumentar a taxa de juros em 2010.

Assinale-se que, durante as fases de redução da Selic, há uma convergência entre os interesses representados pelas duas convenções. A redução da remuneração dos títulos do Tesouro e as medidas institucionais que reduziram o risco do crédito pessoal e habitacional, estimulam o sistema financeiro a ampliar sua oferta de crédito. Como a remuneração destas operações cai menos que a Selic, a expansão do crédito aumenta a rentabilidade do sistema financeiro. Associada ao aumento da massa salarial, a expansão do crédito possibilita forte aumento do consumo familiar e condições mais favoráveis para a operação das empresas. Estabelecida entre 2005 e 2008, a convergência rompeu-se com a crise, quando o sistema privado contraiu sua oferta de crédito. Em resposta, sob a orientação do Ministério da Fazenda, os bancos públicos ampliaram substancialmente sua participação no mercado, reforçando o peso político da convenção desenvolvimentista. A convergência restabeleceu-se no segundo semestre de 2009.

A valorização do câmbio, agravada recentemente, fornece evidência adicional sobre as relações entre as duas convenções. Denunciada como causa de "doença holandesa", torna a indústria localizada no país pouco competitiva no mercado externo e na competição contra importações, e, no limite, ameaça a economia brasileira de desindustrialização (Bresser-Pereira, 2008). A manter-se a valorização do câmbio, o estímulo a investimentos industriais no país seria reduzido e haveria perda de densidade das cadeias produtivas, reduzindo os efeitos de encadeamento e sinergia e a capacidade de inovação associada às relações próximas entre vendedores e produtores.

A valorização está associada a movimentos da conta de capitais, alimentados pela alta taxa de juros brasileira e pela busca de aplicações rentáveis por investidores externos. Conta com a inequívoca simpatia do BACEN, que vem tomando medidas para ampliar a liberalização do câmbio, e dos atores no mercado de crédito e de capitais. Ambos atribuem a valorização aos "funda- 
mentos" da economia brasileira. Em contrapartida, refletindo a convenção neodesenvolvimentista, o Ministério da Fazenda manifesta-se contra a valorização e estabeleceu em 2009 uma taxação sobre a entrada de capitais destinados a investimentos mobiliários, que, embora tenha valor simbólico, é de eficácia limitada.

Mais eficaz do ponto de vista desenvolvimentista foi a política fiscal, especialmente no combate à crise de 2008-9. ${ }^{12}$ A meta de superávit primário foi reduzida para $2,5 \%$ do PIB e os investimentos da Petrobras excluídos do cálculo. O consumo das famílias foi fomentado pela antecipação do aumento do salário mínimo, pelo aumento do valor e da cobertura da Bolsa Família e pela redução de impostos sobre bens de consumo. $\mathrm{O}$ investimento foi estimulado pela ampliação de recursos do BNDES e pela redução da TJLP, assim como por incentivos fiscais para bens de produção e pela manutenção dos investimentos do PAC, ampliados por um novo programa de habitação popular. No entanto, o Ministério da Fazenda já anunciou a volta, em 2010, à meta de superávit primário de 3,3\% do PIB, respondendo à "normalização" das condições econômicas.

Existem, porém, "pontes" entre as duas convenções, que reduzem os conflitos entre elas e, ao mesmo tempo, consolidam a hegemonia da convenção de estabilidade. Entre estas, destaca-se a percepção de que os "pobres" tendem a ser os mais prejudicados em períodos de alta inflação e o sucesso político das políticas de inclusão, que, obtido com baixo custo fiscal e taxas de crescimento relativamente restritas, reduz a importância de altas taxas de crescimento como instrumento de legitimação política, típica do desenvolvimentismo, seja em seu período democrático (os "50 anos em 5"), seja no período autoritário ("ninguém segura este país”) e permite a conciliação entre as duas convenções.

A interpretação dominante sobre a crise de 2008-9 reforça esta correlação de forças. Argumenta-se que a crise foi causada exclusivamente por fatores exógenos, gerados nos países mais desenvolvidos. No Brasil, inexistiriam fatores estruturais que o tornassem propenso a crises - ao contrário, os "fundamentos" da economia brasileira seriam mais sólidos que os daqueles países e o Estado brasileiro mostrou-se extremamente eficaz na reação à crise. A rápida recuperação da economia, a partir do segundo semestre de 2009 e a expectativa de uma volta aos patamares de crescimento e inflação pré-crise seriam a demonstração inequívoca de que a convenção de desenvolvimento existente é a melhor possível.

Em síntese, a convivência entre as duas convenções se estabelece sob a hegemonia da convenção institucional restrita, assegurada pelo controle do tripé de políticas macroeconômicas e pelo fato das políticas neo-desenvolvimentistas não ferirem os interesses representados pela convenção instituciona-

\footnotetext{
${ }^{12}$ Uma descrição minuciosa das medidas tomadas, com as referências aos atos jurídicos, encontra-se em PAC (2009).
} 
lista restrita, desde que as políticas em que esta última se materializa sejam mantidas. A combinação entre as duas convenções atende a uma ampla gama de interesses, que a torna muito forte, nos termos antes definidos.

\section{Convenções alternativas}

Conforme apontado acima, em toda sociedade complexa existem várias convenções de desenvolvimento que disputam a hegemonia. No Brasil contemporâneo destacam-se duas visões críticas às convenções acima descritas.

De um lado, há uma forte reação liberal ao desenvolvimentismo presente no governo Lula, notadamente ao aumento da participação do Estado na economia. Criticam-se o protagonismo das empresas e bancos públicos, a carga tributária e o aumento dos gastos correntes. Dados, porém, o colapso do modelo liberal no mundo e o seu desempenho no Brasil, a probabilidade que esta venha a se tornar uma convenção dominante parece remota.

De outro lado, economistas, principalmente de origem pós-keynesiana, críticos da convenção liberal, têm levado à frente um conjunto de estudos e propostas de política econômica que tem a intenção de fundar uma nova convenção de desenvolvimento, aplicável aos países de renda média. Reunidos sob a expressão "novo-desenvolvimentismo", buscam a "virtus in medio", situando-se, no plano político, entre o liberalismo e o socialismo e, no plano econômico, entre o desenvolvimento endógeno e a integração internacional (Sicsu, de Paula \& Michel, 2005; Sicsu \& Vidotto, 2008).

Uma sistematização recente dos aspectos macro-econômicos (Bresser-Pereira e Gala, 2010) enfatiza sua especificidade, demarcando as diferenças com o tradicional pensamento estruturalista latino-americano (por exemplo, em relação à "complacência" com a inflação e os déficits públicos e à centralidade da política industrial) e, notadamente, com o mainstream neoliberal. Contra este, argumenta que a "nação" é o agente responsável pela definição da principal instituição para o desenvolvimento - uma "estratégia nacional" 13 e que, portanto, as trajetórias de desenvolvimento tem especificidades nacionais. Ainda no plano institucional, defende o fortalecimento do Estado, notadamente, de sua capacidade de regular os mercados e executar políticas industriais "estratégicas”.

Do estruturalismo, recupera a existência, nestes países, de tendências à valorização da taxa de câmbio, causando os problemas da "doença holandesa" (Bresser-Pereira, 2008) e ao crescimento dos salários inferior aos aumentos de produtividade, que acarreta problemas de distribuição de renda e falta de demanda efetiva. Finalmente, contrapõe-se fortemente à ideia, compartilhada por neoliberais e antigos desenvolvimentistas, de que o desenvolvimento tenha que ser financiado por poupanças externas.

${ }^{13}$ A esse respeito, ver também Sicsú (2008). 
Em consequência, propõe uma política macro-econômica distinta da atual, em que a taxa de câmbio seja administrada, inclusive através de controles de capitais, visando a uma taxa de equilíbrio industrial, o padrão fiscal seja mais rigoroso em termos de déficit público e que a política de rendas seja tal que os salários cresçam de acordo com os aumentos de produtividade.

A recuperação da "nação" como agente econômico e de uma "estratégia nacional de desenvolvimento" como instituição traz ao primeiro plano a problemática da economia política em termos da composição de interesses do "agente nacional" e da estratégia de desenvolvimento a ser seguida.

\section{CONCLUSÕES}

Argumentamos acima que o processo de desenvolvimento requer um dispositivo congnitivo coletivo, composto por conhecimentos codificados e tácitos, que permita hierarquizar problemas e soluções e facilitar a coordenação entre os atores sociais - uma convenção de desenvolvimento. Esta convenção reflete a distribuição de poder econômico e social na sociedade, constituindo, pois, um objeto de economia política.

Atualmente, após o fracasso da convenção neoliberal, não há, internacionalmente, uma convenção de desenvolvimento hegemônica. Embora a crise em curso tenha descartado alguns postulados como a capacidade de autorregulação dos mercados e tenha recolocado o Estado num papel central, a indefinição quanto a uma convenção de desenvolvimento foi provavelmente ampliada. A saída da crise nos países desenvolvidos atua a favor das forças, notadamente o capital financeiro internacional, que têm interesse em retornar, tanto quanto possível, ao status quo ante.

No governo Lula, havia, desde o início, o reconhecimento da necessidade de uma nova convenção de desenvolvimento e que, no governo duas convenções disputavam a hegemonia, a que chamamos de "institucionalista restrita" e "neodesenvolvimentista". As convenções apresentam "visões de mundo" e núcleos duros analíticos distintos e são, portanto, ontológicamente conflitivas. A convivência entre elas se dá através da hegemonia da primeira, que privilegia a estabilidade de preços ao custo de um desenvolvimento restrito.

Sumariamente, a hegemonia é explicada, de um lado, pela força da coalizão conservadora que sustenta a primeira, somada à percepção de que as políticas desenvolvimentistas e de inclusão não prejudicam os interesses desta coalizão e, de outro, pela percepção de que taxas de crescimento restritas não obstam a inclusão social e que os "pobres" são os mais prejudicados pela alta inflação.

A convivência das duas convenções atende a uma ampla gama de interesses, que confere-lhe força. Esta é ampliada pela retomada da atividade econômica após a crise, que enseja a interpretação de que a crise foi de natureza exógena e o desenvolvimento em curso satisfatório. No entanto, a médio pra- 
zo, a contradição entre investimentos produtivos e a política macro de juros altos e câmbio valorizado tende a exacerbar os conflitos.

Conforme previsto pelo quadro analítico proposto, as duas convenções presentes no Governo não exaurem o debate. Na sociedade civil estão presentes pelo menos duas convenções que radicalizam o debate - uma convenção mais liberal, que se opõe à ampliação dos papeis do Estado e outra convenção autodenominada "novo-desenvolvimentista", que propõe uma síntese entre elementos de origem keynesiana e do antigo desenvolvimentismo que leva a políticas macro distintas das atualmente em vigor.

Para concluir, chamamos a atenção para o fato de que nenhuma das duas convenções em disputa no Governo enfrenta os problemas da transformação do Estado, notadamente as reformas política, fiscal e administrativa, que, a nosso juízo, são essenciais para um processo de desenvolvimento alto, sustentável e inclusivo. Possivelmente, a explicação para este silêncio encontra suas raízes na governança que caracteriza o presidencialismo de coalizão brasileiro e que acaba por induzir a dependência em relação à trajetória passada e tem, assim, um forte viés conservador.

\section{REFERENCIAS BIBLIOGRÁFICAS}

BARBOSA Fo $F^{\circ}$ N. (2009) "Estimando e revisando o produto potencial do Brasil: uma análise do filtro Hendrick-Prescott com função de produção” em D. Gentil e R. Messemberg, orgs. Crescimento Econômico: Produto Potencial e Investimento, Rio de Janeiro: IPEA.

BERNANKE, B. (2007) "Inflation expectations and inflation forecasting", National Bureau of Economic Research Summer Institute, Cambridge, Mass.

BEVILAQUA, A.; MESQUITA, M. and MINELLA, A. (2007) "Brazil: taming inflation expectations", Working Paper Series n.129, Brasília: Banco Central do Brasil.

BIELSCHOWSKY, R. (1988) Pensamento econômico brasileiro: o ciclo ideológico do desenvolvimentismo, Rio de Janeiro: IPEA.

BRESSER-PEREIRA, L. C. (2008) “The Dutch disease and its neutralization: a Ricardian approach", Brazilian Journal of Political Economy, 28 (1)

BRESSER-PEREIRA, L. C. e GALA, P. (2010) "Macroeconomia estruturalista do desenvolvimento e novo-desenvolvimentismo" Revista de la Cepal, n.100.

BRUNO, M. (2007) "Financiarisation et accumulation du capital productif au Brésil. Les obstacle macro-économiques à une croissance soutenue”, Revue Tiers Monde n. 189.

CASTRO, A. B. (1993) "Renegade development: rise and demise of State-led development in Brazil", em W. Smith, C. Acuña e E. Gamarra, orgs. Democracy, Markets and Structural Reform in Latin America, Londres: Transaction Books.

CHOI, Y. (1993) Paradigms and Conventions: Uncertainty, Decision Making and Entrepreneurship, Michigan: The University of Michigan Press.

DE WOLF, T. and HOLVOET, T. (2005) "Emergence versus self-organisation: different concepts but promising when combined" em Bruekner et al., orgd. Engineering Self Organizing Systems: Methodology and Applications, Berlim: Springer- Verlag.

DENZAU, A. and NORTH, D. (1994) “Shared mental models: ideologies and institutions", Kyklos, 14 (1).

ERBER, F. (2002) “The Brazilian development in the nineties - myths, circles and structures", Nova Economia vol. 12 (1). 
ERBER, F. (2008) “The evolution of development conventions”, www.ie.ufrj.br, XII International Schumpeter Society Conference.

ERBER, F (2009) "Convenções de desenvolvimento no Brasil contemporâneo - um ensaio de Economia Política.", Insight Inteligência, ano XI n. 44.

FILGUEIRAS, L. e GONÇALVES, R. (2007) A política econômica do Governo Lula, Rio de Janeiro: Contraponto Editora.

FURTADO, C. (1961) Desenvolvimento e Subdesenvolvimento, São Paulo: Fundo de Cultura.

FURTADO, C.(1974) O Mito do Desenvolvimento Econômico, Rio de Janeiro: Paz e Terra.

JODELET, D. (1989) Les représentations sociales. Paris: Presses Universitaire de France.

MODENESI, A. (2008) "Convenção e rigidez na política monetária: uma estimativa da função de reação do BCB - 2000-2007”, Texto para Discussão n. 1351, IPEA, Rio de Janeiro.

NORTH, D. (1990) Institutions, Institutional Change and Economic Performance, Cambridge: Cambridge University Press.

Ministério da Fazenda (2003) Política econômica e reformas estruturais, Brasília.

ORLÉAN, A. (2004) L'économie des conventions: définitions et résultats, in A. Orléan (ed.) Analyse économique des conventions, Paris: Presses Universitaires de France.

PAC - Programa de Aceleração do Crescimento (2009) Balanço do PAC - 2 anos, PAC, Brasília.

SÁ EARP, F. (2000) "A tríplice revolução keynesiana: notas sobre a dinâmica da difusão das ideias econômicas", Ensaios FEE, ano 21, n.2

SALLUM JR., B (2000) “O Brasil sob Cardoso: neoliberalismo e desenvolvimentismo", Tempo Social:Revista de Sociologia da USP, 11 (2).

SAFATLE, C. (2009) “Reservas podem chegar a US\$ 300bi”, Valor Econômico, 20/11/2009.

SCHÖN, D. (1988) "Generative metaphor: a perspective on problem-setting in social policy", in A. Ortony, org. Metaphor and Thought. Cambridge: Cambridge University Press.

SICSÚ, J. (2008) "Planejamento estratégico do desenvolvimento e as políticas macroeconômicas" em J. Sicsu e C. Vidotto, org. Economia do desenvolvimento - teoria e politicas keynesianas, Rio de Janeiro: Elsevier.

SICSÚ, J., De PAULA, L. e Michel, R. (2005) Novo-Desenvolvimentismo: Um Projeto Nacional de Crescimento com Equidade Social, Barueri: Editora Manole.

Valor Econômico (2008) Lucro dos bancos triplica no governo Lula, 1/4/2008. 